\title{
Precarious Data: Crack, Opioids, and Visualizing a Drug Abuse Epidemic
}

\section{Candice Welhausen}

\author{
Auburn University, Auburn, Alabama, United States
}

Objective

I analyze a collection of data visualizations created during the crack and opioid epidemics, respectively, published by mainstream news media using three criteria: genre, subject matter, and language used to describe the graphic. I use precarity as a theoretical framework--that is, "a politically induced condition in which certain populations suffer from failing social and economic networks of support and become differentially exposed to injury, violence, and death" (Butler, 2009, p. 35)--to argue that visualizations created during the crack epidemic positioned addicts as criminals whereas opioid addicts have been positioned as patients in need of treatment.

\section{Introduction}

In late 2015, two economists studying health-related data inadvertently discovered an alarming trend: death rates for middle-aged, white Americans were dramatically increasing from drug overdoses (Kolata, 2015), particularly opioids (CDC, 2015). The opioid epidemic has since been widely publicized in the media. However, as critics have argued, the government's response to the crack epidemic differs dramatically from an arguably equally devastating "drug epidemic" that hit many inner US cities thirty years ago - the influx of crack cocaine. More specifically, opioid addicts, who tend to be white, have been positioned as patients, whereas in the 1970s and 80s during the war on drugs, heroin and crack addicts, respectively, who tended to be people of color, were criminalized (Hart, 2017; Hutchinson, 2017).

\section{Methods}

I collected data visualzations created during the crack epidemic for 1/1/86-12/31/92 and for the opioid epidemic from 11/3/15 (the date the NYT covered Case and Deaton's study)-9/30/18 for opioids from the following mainstream news organizations: Newsweek, The Chicago Tribune, The Los Angeles (LA) Times, The New York Times (NYT), The Washington Post (WaPo), Time Magazine, U.S.A Today, and U.S. News and World Report. I then organized each collection by genre (bar or pie chart, line graph, map, etc), subject matter (crime-related, drug use and abuse related, effects on children, effects on health including deaths and treatment, STDs, and trafficking), and also assessed whether the text in the article directly referred to the graphic and discussed the data shown.

\section{Results}

Seventy three images were included of the crack epidemic and 100 were included for the opioid epidemic. The majority of graphics created during the crack epidemic were bar and line graphs whereas there was far more variation in the genre of graphics created during the opioid epidemic. The majority of graphics created during the crack epidemic also showed crime-related information (defined as crime rates, location of crimes, number of crimes committed, specific types of crimes such as homicides as well as information about arrests and sentencing) whereas very few data visualizations created during the opioid epidemic were related to crime. Indeed, the majority of these visuals showed effects on health (more specifically mortality). Finally, data visualizations create during the crack epidemic were rarely directed referred in the text of the article, but were usually discussed albeit, along with other visual information. In contrast, data visualizations created during the opioid epidemic were usually directly referenced and overtly discussed.

\section{Conclusions}

I suggest that these results illustrates precarity (Bulter, 2009) by revealing systemic inequalities that protect some people, but leave others vulnerable through two counter narratives: opioid addiction is a public health issue, but crack addiction is a crime.

\section{References}

Butler J. (2009). Frames of war: When is life grievable? Brooklyn, NY: Verso Books. 
Case A, Deaton A. 2015. Rising morbidity and mortality in midlife among white non-Hispanic Americans in the 21 st century. Proc Natl Acad Sci USA. 112(49), 15078-83. PubMed https://doi.org/10.1073/pnas.1518393112

CDC. (2015). Controlled Substance Prescribing Patterns — Prescription Behavior Surveillance System, Eight States, 2013. Morbidity and Mortality Weekly Report. October 16, 2015 / 64(SS09);1-14.

Hart CL. (2017, August 18). The real opioid emergency. The New York Times.

Hutchinson, E. O. (2017, June 21). The opioid crisis in black and white. Huffington Post.

Kolata G. (2015, November 3). Rise in Deaths for U.S. Whites in Middle Age. The New York Times. 